\title{
Preparation and Properties of Core-shell Structure Fluorine- modified Acrylic Anticorrosion Coatings
}

\author{
Xia Wang*, Hui Wang, Zhang Dai-xiong, Li Hou, Huan Jiang \\ Material science and Engineering School, Southwest Petroleum University, Chengdu 610500, People's \\ Republic of China \\ "E-mail: swpi_wx@126.com
}

doi: $10.20964 / 2019.01 .70$

Received: 1 September 2018 / Accepted: 10 November 2018 / Published: 30 November 2018

\begin{abstract}
A core-shell fluorine modified polyacrylate hybrid latex was successfully prepared by seed emulsion polymerization. The emulsion was characterized by fourier transform infrared spectroscopy and transmission electron microscopy. After the emulsion was prepared on the surface of stainless steel, the surface of the coating was observed. The heat resistance of the coating was analyzed by thermogravimetry, and the corrosion process of the coating was studied by electrochemical experiments. The results showed that the crosslinking degree and the heat resistance of the coating has been improved. The corrosion potential was increased from $-0.46 \mathrm{~V}$ to $-0.17 \mathrm{~V}$ and the current density was reduced from $2.50 \times 10^{-6} \mathrm{~A} / \mathrm{cm}^{-2}$ to $5.54 \times 10^{-8} \mathrm{~A} / \mathrm{cm}^{-2}$ compared with the unmodified coating. The improvement of its anti-corrosion performance is mainly due to the improvement of the shielding effect and surface hydrophobicity. Due to its special core-shell structure, the addition of fluoromonomer to achieve this effect is only $2.36 \%$.
\end{abstract}

Keywords: Coating, Fluorine-modified acrylic, Corrosion protection, Stainless steel, Surface property

\section{$\underline{\text { FULL TEXT }}$}

(C) 2019 The Authors. Published by ESG (www.electrochemsci.org). This article is an open access article distributed under the terms and conditions of the Creative Commons Attribution license (http://creativecommons.org/licenses/by/4.0/). 